\title{
Mobile marketing technology adoption in service SMEs: a multi-perspective framework
}

Article · April 2019

DOI: 10.1108/JSTPM-11-2018-0105

CITATIONS

0

6 authors, including:

Sunday C. Eze

Landmark University

33 PUBLICATIONS 159 CITATIONS

SEE PROFILE

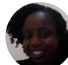

Adenike Bello

Landmark University

11 PUBLICATIONS 12 CITATIONS

SEE PROFILE

Some of the authors of this publication are also working on these related projects:

Project $\quad$ Agri-business value chain View project

Project Unpublished Paper View project
READS

81

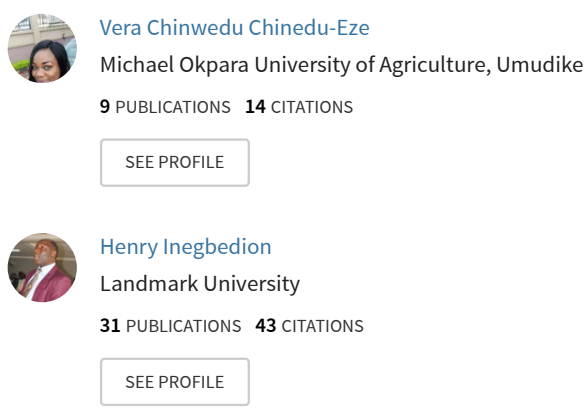




\section{Smart Proof System Instructions}

It is recommended that you read all instructions below; even if you are familiar with online review practices.

Using the Smart Proof system, proof reviewers can easily review the PDF proof, annotate corrections, respond to queries directly from the locally saved PDF proof, all of which are automatically submitted directly to our database without having to upload the annotated PDF.

$\checkmark$ Login into Smart Proof anywhere you are connected to the internet.

$\checkmark$ Review the proof on the following pages and mark corrections,

Annotations changes, and query responses using the Annotation Tools.

Note: Editing done by replacing the text on this PDF is not permitted with this application.

$\checkmark$ Save your proof corrections by clicking the "Publish Comments" button.

Publish Comments

Corrections don't have to be marked in one sitting. You can publish comments and log back in at a later time to add and publish more comments before you click the "Complete Proof Review" button below.

$\checkmark$ Complete your review after all corrections have been published to the server by clicking the "Complete Proof Review" button below.

Before completing your review....

Did you reply to all author queries found in your proof?

Did you click the "Publish Comments" button to save all your corrections? Any unpublished comments will be lost.

Note: Once you click "Complete Proof Review" you will not be able to add or publish additional corrections.

Complete Proof Review 


\section{Mobile marketing technology adoption in service SMEs: a multi-perspective framework}

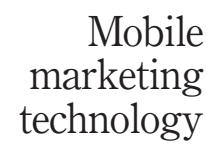

\author{
Sunday C. Eze
}

College of Business and Social Sciences, Landmark University, Оти Aran, Kwara, Nigeria

Vera C. Chinedu-Eze Department of Agri-Business and Management, Michael Okpara University of Agriculture, Umudike, Abia, Nigeria, and Adenike Oluyemi Bello, Henry Inegbedion, Tony Nwanji and Festus Asamu College of Business and Social Sciences, Landmark University, Оти Aran, Kwara, Nigeria
Received 9 November 2018 Revised 12 December 2018 Accepted 20 February 2019

\begin{abstract}
Purpose - The popularity and use of mobile marketing technologies or devices have led to significant interest from researchers and practitioners, particularly in small- and medium-sized enterprises (SMEs), where these technologies offer significant benefits to SMEs given the poor human capital and financial constraints encountered. The use of mobile marketing devices assists SMEs to boost their sales promotion strategies which aim at increasing the sales of their products and services. However, there has been limited focus on developing a suitable framework that enables the evaluation and shared an understanding of the factors influencing the adoption of mobile marketing technology by service SMEs in Nigeria. Therefore, this paper aims to develop a theoretically grounded framework for exploring these factors and explaining their impact on mobile marketing technology adoption in SMEs in Nigeria.
\end{abstract}

Design/methodology/approach - The study is qualitative and used both unstructured and semistructured interviews with a total of 26 participants drawn purposively from NIJA database in Nigeria. Thematic analysis was deployed in analysing the data.

Findings - The study developed an extended technology organisation environment (TOE) framework by incorporating the value anticipation context which helped to unveil 16 key factors influencing mobile marketing technology adoption in service SMEs in Nigeria. The finding revealed that factors associated with the extended TOE framework have an impact on SMEs mobile le marketing technology adoption but at different levels.

Research limitations/implications - The limitation of this study emerged because of the use of qualitative methodologies about the research design, rigour in the collection and management of the large volume of the raw data, the data analysis and the credibility of the findings. This may lead to unforeseen respondent and research bias in the data analysis, which may lead to a limited understanding of alternatives and insights into the factors influencing the adoption of mobile marketing. Hence, other measures and approaches such as case study and mix-method could be deployed to validate the findings further. Also, one of the limitations of qualitative study has been the issue of theoretical generalizability of the framework. The generalizability of the formwork needs to be established across a broader range of the population. Future studies may apply confirmatory statistical techniques to test and ascertain the validity and reliability of the framework across a broader population of mobile marketing technology adopters in Nigeria. Such studies may be used as a benchmark for the theoretical constructs and the factors that may lead to the success or failure of mobile marketing technology adoption.

Originality/value - The study had further enriched TOE framework and provided an analytical dimension for exploring the adoption of mobile marketing technology. It also demonstrates the capacity to

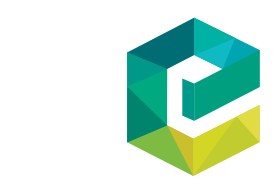

Journal of Science and Technology Policy Management c) Emerald Publishing Limited $2053-4620$ 
provide a reliable explanation of the factors and serves as a tool for evaluating the benefits or challenges of mobile marketing technology adoption in SMEs in Nigeria.

Keywords Nigeria, Theory, Adoption, SMEs, TOE, Mobile marketing technology

Paper type Research paper

\section{Introduction}

The development of information and communication technology (ICT) particularly the use of mobile technology for marketing is expanding both in interest and relevance (Balasubramanian et al., 2002; Charoensukmongkol and Sasatanun, 2017; Shankar et al., 2010; Shankar and Balasubramanian, 2009). This offers opportunities for large and small businesses (Amirkhanpour et al., 2014) to improve their marketing strategies on a daily basis. As the growth of these mobile devices such as internet access devices, cell phones, digital music players' increase, their adoption and use by small businesses are also on the rise (Ma et al., 2009; Shankar et al., 2010). Mobile Marketing Association (2015) defines mobile marketing as the use of wireless media as integrated content delivery and direct response vehicle within a cross-media marketing communication programme. Leppäniemi et al. (2006) view mobile marketing as marketing communication using mobile media; mobile advertising; wireless marketing; and wireless advertising. In this research, mobile marketing technology is defined in this work as these mobile device or technology used by two or multiple persons for communication and promotion of an offer between a firm and its customers (Balasubramanian et al., 2002). It is regarded as the most dynamic, practical and personal marketing strategy because it provides continuous access to consumers anytime and anywhere (Lamarre et al., 2012).

The use of mobile marketing technology is fast becoming a crucial marketing communication tool (Leppäniemi and Karjaluoto, 2008; Inegbedion, 2018). It has increased globally at the rate of 24 per cent in a year from 2000 to 2008, which accounted for about four billion in December 2008 (Shankar et al., 2010). A study in the USA confirms that majority of the US consumers are mobile users (Strom et al., 2014), while in the UK, about 71 per cent of the customers have spent more using mobile applications (Park and Yang, 2006). An emarketer study conducted in 2014 reveals that global mobile marketing technology expenditure in 2014 amounted for US\$17.96bn. This figure is predicted to multiply at the end of 2016. Sultan et al. (2009) also report that 90 per cent of businesses are significant stakeholders in adopting mobile marketing applications and nearly two-thirds of the businesses dedicated approximately 25 per cent of their total marketing budget to mobile marketing devices. It is evident that the use of mobile marketing technologies is no longer a matter of choice. Instead, it has become tools for the survival of both big and small businesses (Earl and Feeny, 2012).

Furthermore, empirical evidence shows that small and medium scale enterprises cannot achieve competitiveness and remain profitable without proper adoption of technology at the right market levels (Harvie, 2010; Lip-Sam and Hock-Eam, 2011; Thurasamy et al., 2009). Hence, mobile marketing applications are becoming relevant to small- and medium-sized enterprises (SMEs). Small businesses adopt these applications to communicate with their clients and customers and initiate business transactions. Mobile devices serve as a medium through which a company interact with customers and partners (Stump et al., 2008). Because of the importance of mobile devices concerning time and location, it is gradually changing the paradigm of SMEs (Sultan et al., 2009; Shankar et al., 2010). Small business interacts with their customer through mobile applications, and for the fact that these devices are ever present, both the firm and its clients can be anyplace anytime to carry out business 
transactions (Shareef et al., 2017; Kim et al., 2008 and Nasco and Bruner, 2008). Therefore, the use of mobile marketing devices is regarded as a substitute for virtual marketing and assist SMEs to boost their sales promotions strategy and increase the sales of their products and services. The peculiar nature and the mobility of mobile marketing applications distinguish it from any another form of promotional and communication tools, which today is considered to have a massive implication for small businesses.

Despite the potentials of mobile marketing technologies to SMEs, most researchers in this area have primarily deployed the conventional philosophies in studying mobile marketing technology. An adoption considers mobile marketing technology adoption as a straightforward, one-off event, and also rely extensively on quantitative methods that conceptualise variables as constructs and predict their levels of the outcome at a single stage (Williams et al., 2009; Eze and Chinedu-Eze, 2018; Silver, 2007; Eze et al., 2018). Gilmore and Carson (2007) argued that examining issues that relate to SMEs is not only about testing variables but recognising the all-inclusive dimensions of SMEs has many benefits. Little is known about how factors influencing the adoption of mobile marketing technology in SMEs are established through a theory grounded framework as most studies that focussed in this area extrapolate the findings of western scholars as if Nigeria operate in the same environment with those in developed nations. In addition, majority of the conventional theories of mobile marketing technology adoption are not designed for SMEs (Xu et al., 2007; Martin and Matlay, 2001) because of their narrow views (Rantapuska and Ihanainen, 2008), and no frequently used theory satisfactorily describes small firm adoption decision because each one of them ignores an important aspect of small business idiosyncrasy (Dwivedi et al., 2009a). Hence, the strategic importance and relevance of SMEs in the economic development of Nigeria and the apparent dearth of local scholarships that provide a guide to this kind of study in Nigeria necessitate this study. Against this background, the paper attempts to examine factors influencing SMEs' adoption of mobile marketing technologies in Nigeria to develop a theory grounded framework that may guide SMEs and researchers in exploring and predicting mobile marketing adoption behaviour among SMEs in Nigeria. This may further provide the basis for timely launching of successful attacks and counter-attacks on rivalries as most small business owners are still sceptical about the adoption and usage of these technologies (Shareef et al., 2017).

\section{Literature review}

\section{Small-and medium-sized enterprises' adoption of mobile marketing}

SMEs across the globe contribute immensely to the economic growth, development and job creation (Parellada et al., 2011; Mutula and Brakel, 2006; Shane 2003). They have continued to expand rapidly because of the numerous assistance received by the government and its agencies (Ongori and Migiro, 2010; Lee, 2004). In Europe for instance, small businesses represent about 90 per cent of the entire businesses and largely contribute to employment generation, innovation development, skills development and accounted for 65 per cent of gross added value (Castro et al., 2010; Lindermann et al., 2009; Martin and Halstead, 2004; Ritchies and Brindley, 2005). Though, with the emergence of globalisation and the shift towards the adoption and use of mobile technologies, there has been a transformation between the past and the future of small businesses (Milla and Choi, 2011) which today, have boosted the operations of SMEs in Nigeria. The study centred on small service businesses in Nigeria because they are growing rapidly and contribute mainly to Nigeria national output (Awa et al., 2012; Eze and Chinedu-Eze, 2018). The research focusses on service SMEs because Nigerian economy is service oriented and the sector today is regarded as the 
primary economic driver, and the significant efforts to improve the economy of Nigeria largely depends on the service sector (Rantapuska and Ihanainen, 2008).

In Nigeria, the economic potential of mobile technologies has not been fully hitched by small businesses owing to lack of resources and poor technical know-how on how to utilise these devices (Ojeme and Onuba, 2010; Inegbedion et al., 2016). The government of Nigerian have established some agencies like Small and Medium Enterprises Agency of Nigeria, Central Bank of Nigeria (CBN) and micro banks in the past to improve SMEs' creativity, innovation and competitive edge. Presently, the apex bank (CBN) has sets up SME credit guarantee scheme worth N200bn to encourage both manufacturing, service, and agricultural value chain, packaging and distribution of certain primary products on the belief that they have labour force of about 11-300 persons and N300m (Osagie, 2010; Ojeme and Onuba, 2010). Despite the pivotal role played by the government and SME in today's economy, SMEs are still confronted with specific barriers in adopting mobile technology and thus, sceptical in implementing this application (Shareef et al., 2017; Levy and Powell, 2003). Most decisions about mobile technology adoption are private reserves to the manager who may in conjunction with their family members take decisions boarding on its adoption and future strategic choices of the organisation. Owing to the significance of SMEs in economic development, and the dearth of mobile marketing adoption frameworks that may serve as a guide for SMEs in Nigeria to adopt and implement mobile marketing devices necessitated the study.

\section{Theoretical underpinning}

Technology organisation environment framework

Academics have investigated mobile marketing adoption devices using resource-based view (RBV), Rogers innovation models (Rogers, 1983, 1995), and several other extensions (Venkatesh et al., 2003), Porter's model (Porter and Millar, 1985), and others involving the meta-analysis of these models (Premkumar, 2003; Adams et al., 1992; Pavlou and Fygenson, 2006) and Intention and behavioural based models (Ajzen and Fishbein, 1980; Davis, 1989). Today, these theories and models are regarded as most regularly used adoption theories to describe IT adoption decisions in SMEs (Parker and Castleman, 2009; Williams et al., 2009). Although these theories have made vital contributions in mobile marketing technology adoption research, the majority of these theories developed were not designed bearing the characteristics of SMEs in mind (Rantapuska and Ihanainen, 2008). According to Dwivedi et al. (2009a) no frequently used ICT adoption theory sufficiently explains SMEs adoption strategy because each of these theories ignored one vital aspect of SMEs or another. Thus, the outcome of their findings resulted in promoting an integrated theoretical framework. According to Rui (2007), the technology organisation environment (TOE) framework absorbs the limitation of the dominant technology perspectives and serves as a useful analytical tool to differentiate the drivers and intrinsic characteristics of an innovation, capabilities and other environmental conditions of the adoption firm. Also, the TOE framework has been adopted by wide range of adoption studies (Alshamaila et al., 2013; Lian et al., 2014; Maclennan and Van Belle, 2014; Ramdani and Kawalek, 2008; Ruivo et al., 2014; Weng and Lin, 2011; Madukua et al., 2016) and illustrates empirical resilience in explaining ICT adoption in organisation (Madukua et al., 2016). The TOE framework has three contextual elements, technology, organisation and environment, which are described below.

Technological context describes the characteristics of the technology within and outside the organisation that are appropriate for the business, and extends to technologies the organisation is using presently, those available in the marketplace but have to been tested 
and those that have not been tried, tested and adopted by the organisation (Gupta et al., 2013; Gutierrez et al., 2015; Oliveira and Martins, 2011). It also denotes both the internal and the external benefits of the technology which are capable of improving the productivity and the operational efficiency of the firm. According to Liao et al. (2003), knowledge acquired internal or external by the firm go a long way to encouraging innovation and organisations must consider the positive changes such innovation will bring to the organisation (Baker, 2012). Technology context in this research implies those internal variables associated with the anticipated performance of the technology that SME managers deliberate before its adopting. It is linked to the much-anticipated benefits that organisations drive from the technology. A number of studies (Alshamaila et al., 2013; Ramdani et al., 2013; Zhu et al., 2003; Markus and Tanis, 2000; Grandon and Pearson, 2004; To and Ngai, 2006; Eze et al., 2013) have investigated variables relating to the technology context such as compatibility, relative advantages and perceived affordability, and provided a theoretical direction for many studies which are relevant in investigating mobile marketing technology adoption. The relative benefits of the mobile devices may shape mobile marketing adoption by SMEs in Nigeria: The organisational context denotes the characteristics of the firm such as the size of the firm, its scope, management structure, degree of centralisation and formalisation, as well the management of its human resources (Tornatzky and Fleisher, 1990).

The environmental context looks at how competition, trading partners, business practice, and government impacts on the organisation (Tornatzky and Fleicher, 1990). Organisation context explains how firm resources and firm characteristics, and firm size, intra-firm communication processes and the lack of resources, influence adoption decisions. In this study, organisation context implies numerous organisation conditions ranging from employee capability to management support which shapes adoption and implementation emerging ICT in several ways which play vital roles in shaping adoption decision of ICT (Baker, 2012). According to Madukua et al., 2016, for IT adoption within the organisation to flourish, top management must communicate the role of the new ICT within the general organisation strategy highlighting the importance of creativity, collaboration within and outside the organisation. This must be achieved based on the level of community (organisation's) engagement with the various actors within and outside the organisation. The level of firms' engagement denotes how well the top management leadership relate to various departments to ensure that each of the department initiatives counts in achieving the goals of the organisation. Firms that encourages a multiplicity of initiatives drawn across the organisation help make the adoption decision easier. Some studies (Ramdani et al., 2013, Thong, 1999; Gutierrez et al., 2015) have examined factors such as perceived employee acceptance and top management support. Even though many of these studies centred on the adoption of ICTs, a large number have not considered that factors are influencing the choice of mobile marketing technology adoption in developing countries.

Environmental context extends to internal and external factors which include the place where the business is piloted, industry structure, regulatory environment of the business, and globalisation (Tornatzky and Fleischer, 1990: Chau and Tam, 1997; Nguyen et al., 2015; Mehrtens et al., 2001). The environment helps in understanding the internal and external variables that shape the adoption of mobile marketing device (Andries and Debackere, 2006). The ability of a firm to have a competitive edge through the examination of the internal environment variable shapes the adoption decision of mobile marketing devices. Thong et al. (1996) stress that top management support influences the ICT efficiency, however external expertise such as IT vendors which also help in the training of SME employees on how to use the new ICT shape its adoption. Also, customers and competition are much more critical for SMEs that conduct their operations in a much more sophisticated 
JSTPM

environment. These factors are linked to the values firms expect from the mobile devices after its adoption within the environment they operate. Factors associated with the environmental context have been discussed extensively in the literature (Oliveira and Martins, 2011; Nguyen, 2009. Ramdani et al., 2013; Mehrtens et al., 2001; Premkumar and Roberts, 1999; Kuan and Chau, 2001).

In summary, the study was underpinned by the TOE framework based on some factors. The TOE framework integrates the environmental context which has to a large extent neglected by Innovation diffusion theory (IDT). This integration has helped in the explanation of the intra-firms innovation adoption better than the IDT (Oliveira and Martins, 2011; Madukua et al., 2016). The TOE is a more robust theoretical base (Alshamaila et al., 2013) which may have the capability to unravel broad factors that may influence the adoption of mobile marketing technologies in Nigeria because is linked with many variables associated technology, organisation and environment factors and provide significant analytical tool for examining the adoption decision of wide-ranging IT innovations (Oliveira and Martins, 2011). The elements of TOE framework forms the bases for the exploration of all-inclusive variables and the development of a framework that may shape the adoption of mobile marketing technology adoption in developing countries and may reduce the uncertainty that is linked to its adoption. The conceptual framework for this study is presented in Figure 1 below.

\section{Methodology}

Research process

This study adopted a qualitative approach in a bid to explore factors influencing the adoption of mobile marketing devices and develop a framework for SMEs in Nigeria. To achieve this objective, the study was conducted in the following manner: the study first reviewed the relevant literature to have a broad view of the subject matter and how the thematic codes were generated during the preliminary study. The study identified the likely empirical codes associated with theoretical underpinning which formed the bases of the research using the raw data collected during the initial stage of the unstructured interviews. This helped to check the credibility of the codes and to place the research in a broader context. The study conducted semi-structured interviews to generate further themes associated with each empirical codes and further validate the findings of the study.

Figure 1. Proposed study framework

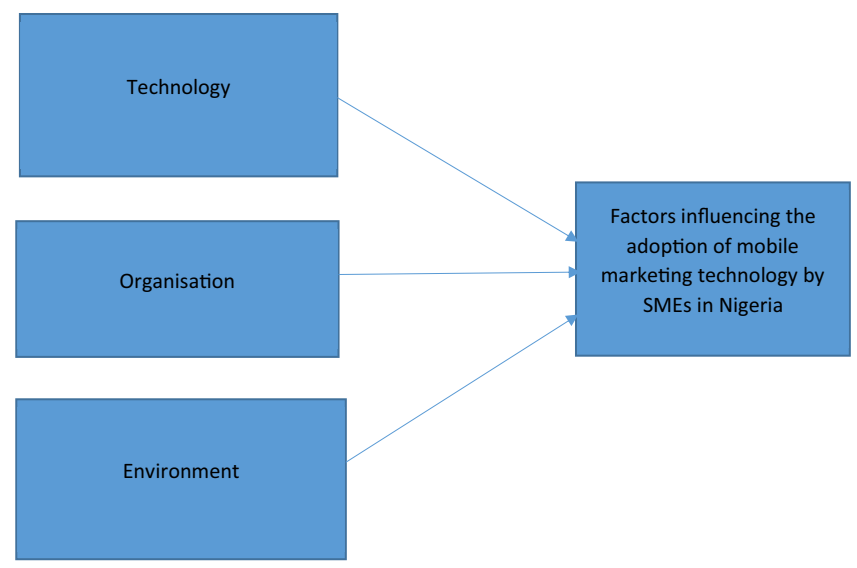




\section{Sampling}

The study adopted purposeful sampling as qualitative research stresses on discovery and interpretation of participants' views and experiences and not for statistical generalisation (Schultze and Avital, 2011). Furthermore, snowball sampling complimented purposeful sampling because, during the initial interviews, the first few participants also introduced the researchers to other key informants that were also interviewed. An early sample of 76 participants was generated from Luton Business Directory of which 25 participants agreed to be interviewed. The sample was selected based on service SMEs that have adopted mobile marketing devices in the past three years and have operated in Nigeria in the past five years. The interview was conducted in two distinct stages.

\section{Interviews}

At Stage 1, or preliminary stage, 11 participants were interviewed using unstructured interview questions. As mentioned earlier, the reason for the preliminary study using the unstructured interview was to understand the current state of mobile marketing technology adoption in service SMEs in a bid to put the study into a broad context. Secondly, to develop empirical codes associated with the TOE framework from the interview for credibility check (Fereday and Muir-Cochrane, 2006: Boyatzis, 1998) and finally, to develop an initial framework. The purpose of this exercise was to ensure that the codes applied to the raw data and those that would be used in the validation of the findings (see Stages 1 and 2 of the data analysis process in Figure 1). It is important to note that at the preliminary stage of this research, an initial reliability test was carried out to enable the researchers to gain confidence that the initial empirical codes would be applied to subsequent raw data, and four colleagues related the quotes against the categories before the preliminary framework was developed. This is what necessitated the development of the semi-structured interview questions.

At Stage 2, 15 semi-structured interviews were carried to enhance the empirical codes and to help validate and confirm the findings of this study. The unit of analysis was SMEs managers that have engaged with mobile marketing. The initial framework developed after the preliminary study guided the participants during the semistructured interviews and aided the description in a manner that the established features of the framework were discovered (Schultze and Avital, 2011). All the interviews were recorded and transcribed verbatim. Table I below presents the interview profile. Before the interview proper, a formal letter was written, duplicated and sent to the interviewees describing the purpose of the research and also addressed the confidentiality issues. The interviews lasted for 1-1.45 h. The raw data were transcribed verbatim afterwards, and a data-driven thematic analysis approach was further used to code the raw data to post-defined categories which allowed themes to emerge inductively. Table I shows the interview profile for the study.

\section{Data analysis}

The study implemented data-driven thematic analysis in analysing the data. Although TOE framework formed the bases for the study, the codes associated with TOE are empirically driven and their features written in more straightforward terms (Table II) using the code name, the definitions of the codes and their description (Miles and Huberman, 1994). This also assisted in the credibility and dependability checks. Also, Figure 1 shows the step by step data analysis process. Stages 1-3 were applied with the initial raw data used for the preliminary study using the unstructured interview data. At Stage 4, all the transcribed data (unstructured and semi-structured interview data) were imported into NVivo (Stage 4 of 


\begin{tabular}{|c|c|c|c|c|}
\hline \multirow[t]{6}{*}{ JSTPM } & $\begin{array}{l}\text { Interview } \\
\text { participants }\end{array}$ & Position & Company size & Type of service \\
\hline & $\mathrm{Z1}$ & Director & 65 & Security \\
\hline & $\mathrm{Z} 2$ & Manager & 105 & Internet marketing and advertising \\
\hline & Z3 & IT manager & & \\
\hline & $\mathrm{Z4}$ & IT manager & & \\
\hline & $\mathrm{Z5}$ & Chief Executive & 25 & Social media/consultancy \\
\hline & & Officer & & \\
\hline & Z6 & Director & 48 & Social network provider \\
\hline & $\mathrm{Z7}$ & Managing Director & 110 & IT Vendor/Consultancy \\
\hline & Z8 & Manager & 110 & \\
\hline & $\mathrm{Z9}$ & Operational Manager & 75 & Sales and distribution \\
\hline & $\mathrm{Z10}$ & Managing Director & 150 & Construction \\
\hline & Z11 & Director & 20 & IT Vendor/Consultancy \\
\hline & Z12 & Director & 52 & Business and Management/Consultancy \\
\hline & $\mathrm{Z13}$ & $\begin{array}{l}\text { Manager/IT support } \\
\text { staff }\end{array}$ & 208 & IT \\
\hline & Z14 & Manager & 11 & Accounting \\
\hline & Z15 & Manager & 55 & IT and networking \\
\hline & Z16 & Director & 67 & IT \\
\hline & Z17 & $\begin{array}{l}\text { Chief Executive } \\
\text { Officer }\end{array}$ & 240 & IT Quality control \\
\hline & Z18 & Manager & 90 & IT \\
\hline & Z19 & Manage & 11 & IT and networking \\
\hline & $\mathrm{Z} 20$ & Manager & 21 & Consultancy \\
\hline & Z21 & Director & 12 & Education and training \\
\hline & Z22 & Director & 8 & Education and training \\
\hline & Z23 & Director & 11 & Education and training \\
\hline & Z24 & Manager & 22 & support services \\
\hline Table I. & Z25 & Manager & 33 & Support and advisory services \\
\hline Interview profile & Z26 & Manager & 102 & IT consultant/business supports/advice \\
\hline
\end{tabular}

Codes, definitions and descriptions
Technology

Organisation

Environment

Value anticipation
Technology context refers to both the internal and the external factors that influence SMEs adoption of mobile marketing technology

Organisation context refers those resources that shape the adoption of mobile marketing technology adoption of SMEs

Environmental context refers to both the internal and external factors impact organisations adoption of mobile marketing technology adoption

Value anticipation refers to expected benefits arising from the adoption of mobile devices

Figure 2). This facilitated the analysis of the data because of the vast data involved. This process helped in the management of the data with practical guides for coding the data (Table I). Codes were applied within and across cases, after which themes were identified and connected to the model which aid in the interpretation of the findings (Boyatzis, 1998; Johnston, et al., 2013).

Data were retrieved from NVivo in Stage 5 and themed empirical clustered (Boyatzis, 1998). Verification entails further reliability and validity checks. Table V presents the outcome of the reliability analysis using percentage agreement (Boyatzis, 1998) (Table III). 


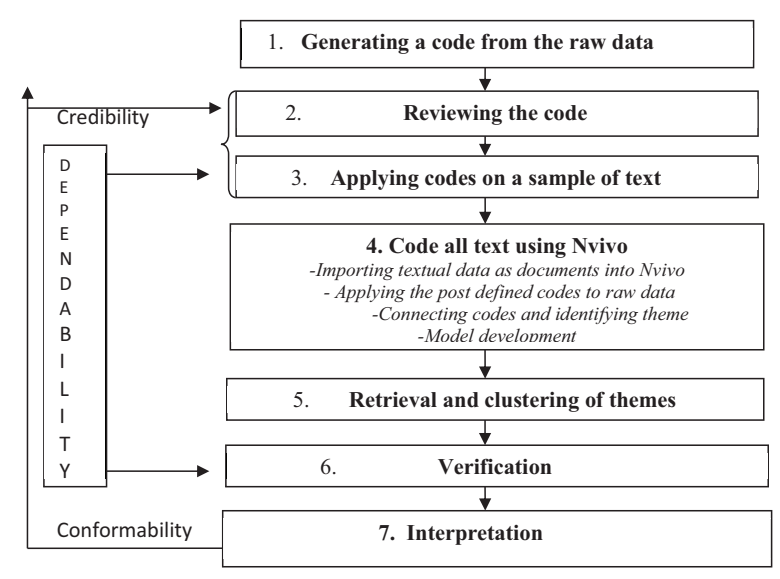

\begin{tabular}{lll} 
Areas & \multicolumn{2}{c}{ Reliability } \\
\hline
\end{tabular}

Factors influencing mobile marketing technology adoption

4

$0.79(79 \%)$

$88(88 \%)$

Table III.

Data analysis process

The researchers validated the study by requesting some experts in the field to look at the pattern in the data about the associated themes. This method unveiled how dependable the data analysed and reported were followed by a confirmation to understand how firmly the raw data is linked to the interpretation (Boyatzis, 1998).

\section{Findings}

T4-8 Tables IV-VIII show the themes associated with each code, supporting cases and supporting AQ: 2 evidence. This study adopted theory-driven thematic analysis method because themes that emerged were generated and clustered based on the characteristics of the theoretical codes (Boyatzis, 1998). This process revealed factors influencing the adoption of mobile marketing technologies in SMEs.

\begin{tabular}{|c|c|c|c|}
\hline Factors (Themes) & Related cases & No. of cases coded & \\
\hline \multicolumn{4}{|l|}{ Technology } \\
\hline Operational effectiveness & $\mathrm{A} 1 * *, \mathrm{~A} 2 * * * * *, \mathrm{~A} 5^{*}, \mathrm{~A} 7^{*}, \mathrm{~A} 9^{*}, \mathrm{~A} 11^{*}, \mathrm{~A} 14^{*}, \mathrm{~A} 15^{*}$ & 8 & \\
\hline Adaptive capability & $\mathrm{A} 1 *, \mathrm{~A} 2 * * *, \mathrm{~A} 3^{*}, \mathrm{~A} 10^{* *}, \mathrm{~A} 13^{* * *}, \mathrm{~A} 14^{* * *}, \mathrm{~A} 16^{*}, \mathrm{~A} 17^{*}, \mathrm{~A} 20^{*}$ & 9 & \\
\hline Simplicity & $\mathrm{A} 1^{*}, \mathrm{~A} 6^{*}, \mathrm{~A} 7 * * * *, \mathrm{~A} 8 *, \mathrm{~A} 9 * * * *, \mathrm{~A} 11^{* * *}, \mathrm{~A} 15^{* * * *}$ & 7 & \\
\hline Safety issues & $\mathrm{A} 1^{* *}, \mathrm{~A} 5^{* *}, \mathrm{~A} 7^{*}, \mathrm{~A} 9^{*}, \mathrm{~A} 15^{*}, \mathrm{~A} 16^{*}, \mathrm{~A} 23^{* *}$ & 7 & \\
\hline Expandability & $\mathrm{A} 2^{*}, \mathrm{~A} 3^{*}, \mathrm{~A} 4^{*}, \mathrm{~A} 12^{*}, \mathrm{~A} 14^{*}, \mathrm{~A} 18^{* *}, \mathrm{~A} 19^{*}, \mathrm{~A} 20^{* *}$ & 8 & \\
\hline Cumulative & $\begin{array}{l}\text { A1, A2, A3, A4, A5, A6, A7, A8, A9, A10, A11, A12, A14, } \\
\text { A15, A16, A17, A18, A19, A20 }\end{array}$ & $19 / 26(73 \%)$ & $\begin{array}{r}\text { Table IV. } \\
\text { Technology related } \\
\text { factors and }\end{array}$ \\
\hline \multicolumn{3}{|c|}{ Notes: A1, A2 = Interviewees; $*=$ no. of references on text } & supported cases \\
\hline
\end{tabular}




\section{The theory grounded framework of mobile marketing technology adoption in small-and} medium-sized enterprises

The theory grounded framework developed in this study has identified key factors influencing the adoption of mobile marketing technology. The above factors presented in the framework in Figure 3 below were based on the categorisation of the three theoretical codes (technology, organisation and environment) and one empirical code (value anticipation) which emerged inductively during the analysis. The exploratory and the explanatory capabilities of the framework and the factors presented below are based on participants'

Table V.

Organisational related factors (themes) and supported cases

\begin{tabular}{llc}
\hline Factors (Themes) & Related cases & No. of cases coded \\
\hline $\begin{array}{l}\text { Organisation } \\
\text { Shared understanding }\end{array}$ & $\mathrm{A} 11^{*}, \mathrm{~A} 5^{*}, \mathrm{~A}, 7^{*}, \mathrm{~A} 8^{* *}, \mathrm{~A} 15^{*}, \mathrm{~A} 19^{*}, \mathrm{~A} 22^{* * *}, \mathrm{~A} 23^{* * * *}$, & 10 \\
Extent of business & $\mathrm{A} 24^{*}, \mathrm{~A} 26^{* * *}$ & \\
$\begin{array}{l}\text { Collaboration } \\
\text { Diversity in knowledge }\end{array}$ & $\mathrm{A} 5, \mathrm{~A} 6^{*}, \mathrm{~A} 7^{*}, \mathrm{~A} 11^{*}, \mathrm{~A} 12^{*}, \mathrm{~A} 16^{*}, \mathrm{~A} 17^{*}, \mathrm{~A} 19^{*}, \mathrm{~A} 13^{*}, \mathrm{~A} 15^{*}$ & 10 \\
Cumulative & $\mathrm{A} 1, \mathrm{~A} 2, \mathrm{~A} 3, \mathrm{~A} 4, \mathrm{~A} 5, \mathrm{~A} 7, \mathrm{~A} 8, \mathrm{~A} 11, \mathrm{~A} 12, \mathrm{~A} 15, \mathrm{~A} 17, \mathrm{~A} 19, \mathrm{~A} 22$, & $16 / 26(61 \%)$ \\
& $\mathrm{A} 23, \mathrm{~A} 24, \mathrm{~A} 26$ & \\
Notes: A1, A2 $=$ Interviewees; $*$ no. of references on the text & \\
\hline
\end{tabular}

\begin{tabular}{lll}
\hline Factors (Themes) & Related cases & No. of cases coded \\
\hline Environment & & \\
Training periods & $\mathrm{A} 1^{*}, \mathrm{~A} 2^{* *}, \mathrm{~A} 5^{*}, \mathrm{~A} 9^{*}, \mathrm{~A} 11^{*}, \mathrm{~A} 13^{* *}, \mathrm{~A} 14^{* *}, \mathrm{~A} 17^{*}, \mathrm{~A} 18^{*}, \mathrm{~A} 20^{*}$ & 6 \\
Service delivery & $\mathrm{A} 2^{* * *}, \mathrm{~A} 3^{*}, \mathrm{~A} 7^{*}, \mathrm{~A} 10^{*}, \mathrm{~A} 11^{*}, \mathrm{~A} 9^{*}, \mathrm{~A} 12^{*}, \mathrm{~A} 15^{* *}$ & 6 \\
Customer satisfaction & $\mathrm{A} 1^{*}, \mathrm{~A} 4^{*}, \mathrm{~A} 5^{*}, \mathrm{~A} 6^{*}, \mathrm{~A} 7^{* *}, \mathrm{~A} 10^{*}, \mathrm{~A} 12^{* *}, \mathrm{~A} 14^{*}$ & 6 \\
Competition & $\mathrm{A} 1^{*}, \mathrm{~A} 5^{*}, \mathrm{~A} 9^{* *}, \mathrm{~A} 13^{* *}, \mathrm{~A} 14^{*}, \mathrm{~A} 16^{*}, \mathrm{~A} 23^{*}, \mathrm{~A} 25^{* *}, \mathrm{~A} 26^{* * *}$ & 6
\end{tabular}

\section{Table VI.}

Environment-related factors and supported cases
A1, A2, A3, A4, A5, A6, A7, A8, A9, A10, A11, A12, A13, A14, 21/26 (80\%) A16, A17, A18, A23, A23, A25, A26
Notes: A1, A2 = Interviewees; $*=$ no. of references in text

\begin{tabular}{llc}
\hline Factors (Themes) & Related cases & No. of cases coded \\
\hline Value anticipation & & \\
Cost & $\mathrm{A} 1^{*}, \mathrm{~A} 2^{*}, \mathrm{~A} 3^{*}, \mathrm{~A} 5^{* * *}, \mathrm{~A} 6^{* * * * *}, \mathrm{~A} 9^{*}, \mathrm{~A} 11^{* *}, \mathrm{~A} 15^{* * *}, \mathrm{~A} 16^{*}$, & 11 \\
& $\mathrm{~A} 20^{*}, \mathrm{~A} 2^{*}, \mathrm{~A} 3^{* *}$ & 5 \\
Business growth & $\mathrm{A} 5^{* * *}, \mathrm{~A} 6, \mathrm{~A} 9^{* *}, \mathrm{~A} 14^{*}, \mathrm{~A} 20^{*}$ & 5 \\
Differentiation & $\mathrm{A} 5^{* * * * * * * *,} \mathrm{~A} 13^{*}, \mathrm{~A} 16^{*}, \mathrm{~A} 17, \mathrm{~A} 20$ & 8 \\
Return on investment & $\mathrm{A} 2^{*}, \mathrm{~A} 5^{*}, \mathrm{~A} 9^{* *}, \mathrm{~A} 12^{* *}, \mathrm{~A} 13^{* *}, \mathrm{~A} 14^{*}, \mathrm{~A} 20^{*}, \mathrm{~A} 23^{*}$ & $15 / 25(58 \%)$ \\
& $\mathrm{A} 1, \mathrm{~A} 2, \mathrm{~A} 3 \mathrm{~A} 5, \mathrm{~A} 6, \mathrm{~A} 9, \mathrm{~A} 11, \mathrm{~A} 12, \mathrm{~A} 13, \mathrm{~A} 14, \mathrm{~A} 15, \mathrm{~A} 16, \mathrm{~A} 17$, &
\end{tabular}

Table VII.

Value anticipation related factors and supported cases

Notes: A1, A2 = Interviewees; $*=$ no. of references in text 
Mobile marketing adoption factors

Code 1: Technology Operational effectiveness

Adaptive capability

Simplicity

Safety issues

Expandability

Code 2: Organisation Shared understanding

Extent of collaboration

Diversity in knowledge

Code 3: Environment Training periods

Service delivery

Customer satisfaction
Samples of supporting evidence

"[-] the mobile device must prove to be efficient and provides similar servers big companies offer" (A5) "The mobile app must demonstrate that it moves the company to the next level" (A2)

"If the application is structured in the same way with the existing ones in the organisation, it is much easy to integrate, we will not adopt such application if it follows a dissimilar pattern. Otherwise it will lead to another learning curves" (A3) "Can the app be easily integrates with already existing ones in the organisation? To what extent does the app interface with those in the organisation?" (A13)

"I am not an IT literate, I struggle with most of the mobile app. It has to be easy to use [- just like the internet, the computer or whatever" (A8) "You know we are from the developing country. Most of these things are new to us. If the mobile application made my life easier in carrying our my business operation, I would be happy embrace it" (A11)

"Can our record be kept with the mobile app for some years and as maintained? If yes we are ready to try the product" (15) "Secure payment is becoming an issue in Nigeria with some of the technologies used which involve several frauds. [-] Online security is a big challenge [-] we will go with, whichever one is much more secured" (A9)

"This is necessary because if you are using a modular solution, it will get to a point, you cannot replicate or make it bigger" (A12) "Can we adopt an app that will take over or accommodate the existing applications we have? That will influence us in trying the new application" (A14)

"Is about coming together, and assessing what we have and also what the application can offer and we take a decision" (A19) I cannot make the decision alone if I want the business to be competitive. I will have to involve other people within and outside the organisation [-]" (A23)

"I am considering the best practice. You see, many SMEs do not like collaborating with others". [-] collaboration regarding what mobile application to adopt especially SMEs within the same line of business is very good even with competition" (A12) "Yes, each staff in the organisation played a team role by working together to ensure that we get an application that will help meet our customers need" (A15)

"[-] Most times we are the innovators driving the mobile app by communicating with the IT people or developers on a daily basis to ensure that the application is in line with our need. They cannot do it alone" (A9) "[-] we have to bring our knowledge, and constantly reviewing what the outcome is. That is when external advice comes to play. You" (A12)

"We need to train which may depend on the time. We will try the mobile app If the time to train our staff is minimal" (A11) "How much time do we require to master the application? If we are going to spend much time, we may adopt it" (A2)

"[-] is the application going to be fast? [-] for us, speed is a determinant factor" (A15) "The main reason why we would try a new mobile application is if it improves our process and delivery" (A12)

"We see our customers like kings, is the mobile application capable of satisfying our customers' needs? This is very important" (A11) "Mobile app is a means to an end we consider it as one of the capabilities to be able to relate with our customers and meet their needs [-]" (A12)

\section{Mobile marketing technology}

Pe

Table VIII.

Factors influencing mobile marketing technology adoption and the sample (continued) 


\section{JSTPM}

Mobile marketing

adoption factors Samples of supporting evidence

Competition "Because they want to compete they just have to keep doing it" (A5) "I was just worried that we might be left behind" (A1) "As long as we want to be

Code 4: Value

anticipation

Cost competitive, we just have to keep adopting new application" (A9)

Business growth

"You know we are small. If is reasonably cheap we will try it" (A1) "[-] cost is one of the critical factors we consider [-]. Would it help us to reduce the total manpower we have" (A15)

"One thing that motivates the search for a new application is growth. Would the application help us to increase our customer base?" (A14) "Can the application help us acquire 30 clients or more in a few months we will try the

Differentiation new app" (A5)

"our need for a new mobile app largely depend on how it can help us reduce cost, [-], and create a niche in a market" (A5) Can the mobile app differentiate us from our competition? [-]. If yes, it is highly likely that we would try the app (A13)

Return on investment "[-] anything technology application that cannot help us maximise our profit, would not be considered" (A20) "If we invest \#10,000, as long as it yields a return of $\# 15,000$ we will adopt it (A23)

narratives, theoretical and empirical codes, and the literature. These provide a valid explanation of the factors influencing the adoption of mobile marketing in SMEs. These factors are now discussed below.

\section{Discussion}

Technology

Operational effectiveness. Operational efficiency in this context entails how proficient the mobile marketing application would help meet the needs of the business. It was revealed that SMEs are always faced with pressure, not only to survive but to become commercially viable. Observation revealed that the economic hardship and the volatile nature of the business environment in Nigeria make the adoption of mobile applications even more difficult even though they are relatively cheap. This hinders most SMEs in adopting the applications due to scarce resources. While some SMEs in developing countries have engaged in mobile marketing applications in their Perspective business to assist in the marketing of the product and to relate with their customers. However, it was primarily echoed by participants that the mobile marketing application would be valued more if the task for which it was sought for such as high performance and efficiency would be accomplished without much complexity.

[-] the mobile device must prove to be efficient and provides similar servers big companies offer without having to be complex (A5).

The mobile app must demonstrate that it can move the company to the next level (A2).

[-] Can the mobile app keep business operation very efficient and provide some of the services big organisations offer? (A7).

Similar points were raised by other interviewees A1, A11, 14 and 15.The finding is consistent with the works of Madukua et al. (2016) and further supported by 

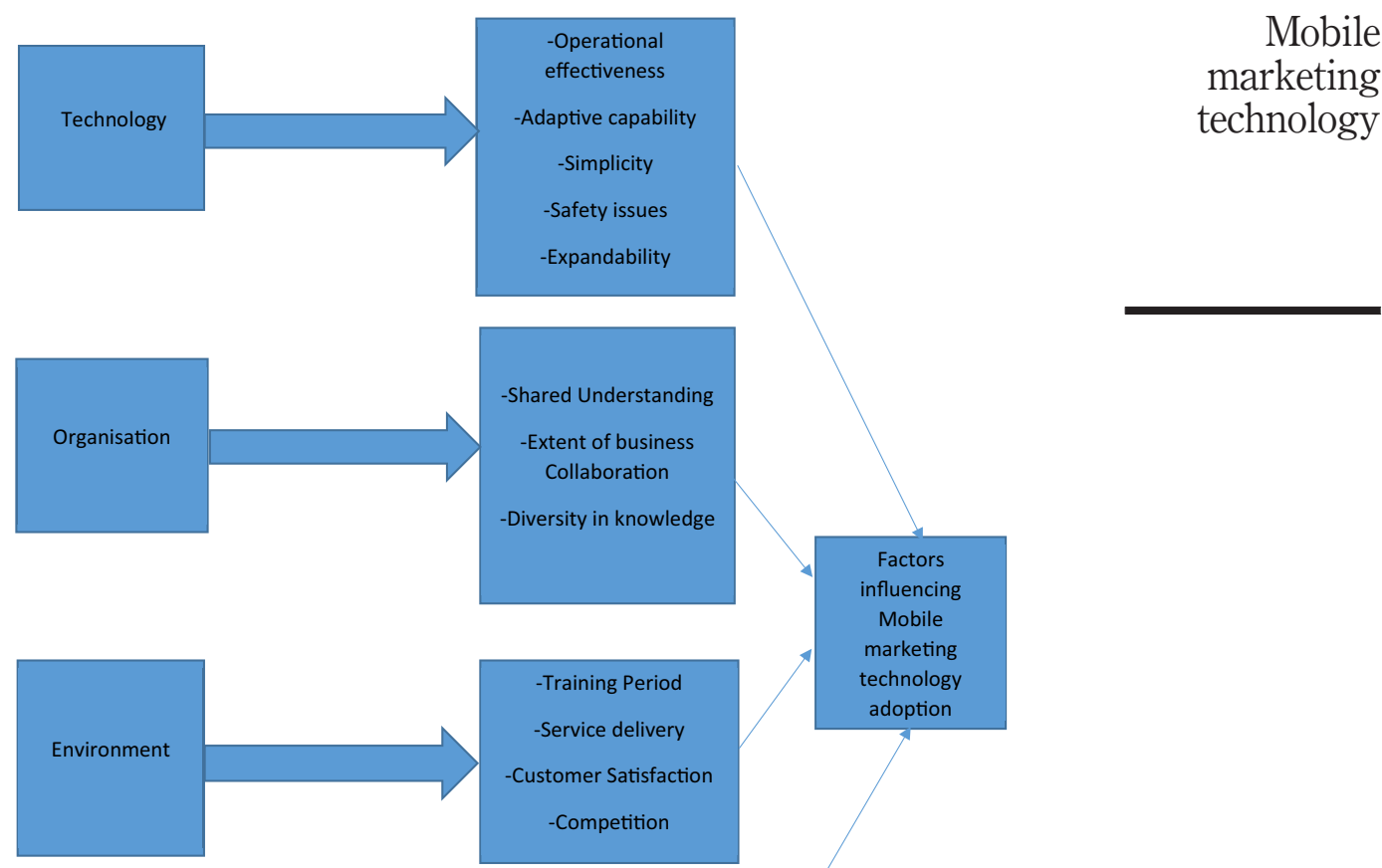

Factors

influencing

Mobile

marketing

technology

adoption

Figure 3.

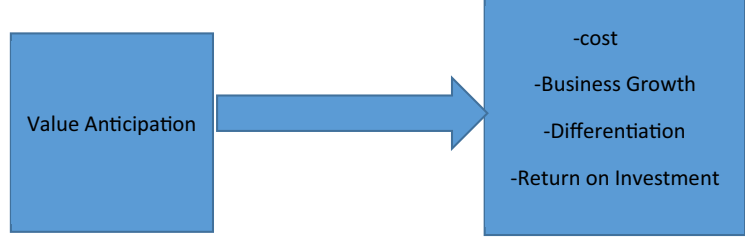

A framework of mobile marketing technology adoption in SMEs

Aboelmaged (2010), Li et al. (2011) and Ramayah et al. (2016). Some studies have also argued that IT application that is complex and slows business operations down will inhibit the widespread of its adoption by SMEs (Brown and Lockett, 2004; Ritchies and Brindley, 2005; Teo et al., 2011; Teo and Pan, 2008).In summary, small businesses would mostly engage with mobile marketing technologies if it is efficient and capable of moving the company forward.

Adaptive capability. Zhu et al. (2003) note that connectivity eliminates incompatibility within the organisation and can also restrict compatibility were the new IT application is difficult to integrate with existing ones in the origination. Adaptive capability defines the extent the new mobile marketing application integrates to both the business operations and the existing IT applications in the organisation. Some participants (e.g. A1, A2, A10 and A14) note that businesses need to identify and at the same time understand the opportunities offered by mobile marketing applications. This requires searching for information about the mobile marketing app, learn to overcome the 
failure by ensuring they adopt and adapt to those that are compatible with the business arrangements. This was further supported by the participants:

If the application is structured in the same way with the existing ones in the organisation, it is much easy to integrate; we will not adopt such application if it follows a dissimilar pattern. Otherwise, it will lead to another learning curves (A3).

Can the app be easily integrated with already existing ones in the organisation? To what extent does the app interface with those in the organisation? (A13).

Furthermore, it was revealed that SMEs are constrained by time, resources and spending time transferring data from an old application to new ones might be a costly venture. As such, adaptive capability as an essential factor to be considered. According to Khoumbati et al. (2006) the inability of integrating an infrastructure with the one ones might be costly as such business most avoid this from the onset. This happens when the features of the new application fail to fit into the existing values of the current organisation's mobile marketing technology needs (Fitzgerald and Kenny, 2003). Adaptive capability shapes mobile marketing technology adoption and SMEs are passionate in trying it if it meets the organisation present and future arrangements.

Simplicity. Majority of IT adoption studies (Hong et al., 2011; Khoumbati et al., 2006; Lip-Sam and Hock-Eam, 2011) argued that most small businesses lack the necessary skills and knowledge to use IT applications. Simplicity implies how easy the mobile marketing application is in carrying out a task for the business. Alternatively, the ease with which the mobile marketing application enables the complex task to be carried out or allows few individuals with littlespecialised knowledge to handle more complex tasks as highlighted by managers:

I am not an IT literate. I struggle with most of the mobile app. It has to be easy to use [-] just like the internet, the computer or whatever (A8).

You know we are from the developing country. Most of these things are new to us. If the mobile application made my life easier in carrying out my business operation, I would be happy embrace it (A11).

I think most people will try the mobile app if it helps businesses to reduce their promotional budget and workforce say 50-25 people and they are still turning over million.Also can someone without experience and little skills operate it? (A7).

This assertion points to the fact that simplicity would be one of the key determinants of the mobile marketing application. It also suggests that most small businesses would not adopt new mobile applications if it is complex and stressful to cope with. Reason being that they are limited in skills and knowledge concerning IT applications. Participants further supported the above comments: A1, A6, A9 and A15. Similarly, studies (Hong et al., 2011; Polites and Karahanna, 2012) note that ease of use is the prerequisite for adoption and use of IT application while others (Moore and Benbasat, 1991; Venkatesh and Davis, 1996) have also found a positive relationship between ease of use and adoption of IT applications.

Safety issues. Safety is defined as the protection of information, persons and property from unforeseen circumstances. IT security infrastructures have remained the basis for the secured environment (Cavusoglu et al., 2004). Safety and security are vital as soon as a business transaction is carried out beyond the boundaries of the offline methods of conducting a business transaction. The analysis shows that safety 
and security issues were still significant concerns for SMEs in Nigeria before any attempt is made in adopting any mobile application. Majority of the participants echoed that if the mobile marketing application is perceived to be unsafe regarding losing access to confidential information, the chance that the application would be adopted would be very low:

Can our record be kept with the mobile app for some years and as maintained? If yes we are ready to try the product (A15).

Secure payment is becoming a big issue in Nigeria with some of the applications used which involves several frauds. [-] Online security is a big challenge [-] we will go with, whichever one is much more secured (A9).

It is safe in that it is backed up [-](A1).

It was further perceived that SMEs might not trust most of the mobile applications as observation revealed that mobile app providers may not be independent thus, trust was also an issue. For example, a participant notes that:

Is not just lack of resources, is trust (A23).

Similarly, Yousafzai and Yani-De-Soriano (2012) in their study found that insecurity is associated with distrust of the application and disbelief about its ability to work effortlessly. The finding suggests that businesses that eventually trust a piece of mobile marketing application may later adopt it if need be. Observation also shows that SMEs would adopt and implement if it can keep track of not just confidential information but also advice employee is when safety issues arise during usage. Security concerns related to both fears of losing data, confidential information and allows managers to monitor their staffs and ensure they are safe at work.

Expandability. Expendability is defined in this context as the capacity of the Mobil marketing device to accommodate new features regularly. It was observed that the flexible nature and the ability of the mobile devices to constantly integrate with new features is the basis for other processes can be achieved. As noted by some participants, expandability of mobile application aid innovation of business process and reduces the cost of developing or adopting entirely new systems. While most SMEs interviewed widely perceived that some mobile applications are flexible and expandable, others are not. The finding suggests that most SMEs would be willing to adopt mobile marketing devices shortly if the applications would accommodate another mobile app. The point was highlighted cross cases:

This is necessary because if you are using a modular solution, it will get to a point, you cannot replicate or make it bigger (A12).

Can we adopt an app that will take over or accommodate the existing applications we have? That will influence us in trying the new application (A14).

Our plan now the idea is to look for an application that would be integrated with the existing systems (A14).

In support of the finding, similar studies (Gholami et al., 2009; Fitzgerald and Kenny, 2003) have found that changes can easily be made to IT applications that are flexible, which may trigger trial. Hence, SMEs are eager to trying new IT applications that would accommodate new functions easily. 


\section{JSTPM}

\section{Organisation}

Shared understanding. Shared understanding is defined as cordial understanding of the organisation purpose and needs between the employer, employees and another external context through open interaction. Observation revealed that the perception of SME managers about the mobile applications might be viewed differently depending on the social setting and knowledge of different persons. Hence, for decisions to be effective, managers must acquire, share, process and disseminates business information that holds not only the same meaning to every individual within and outside the organisation, but the intended mobile marketing application must be understood by all parties involved. As one manager's highlights:

Is about coming together, and assessing what we have and also what the application can offer and we take a decision (A19).

I cannot take the decision alone if I want the business to be competitive. I will have to involve other people within and outside the organisation $[-]$ (A23).

Similarly, Miranda and Sauder (2003) noted that shared meaning is essential in every interaction, and the setting in which the information is disseminated adds to its meaning. Most small businesses lack the necessary IT skills and knowledge, and when there is a conversation with their employees and another external context such as IT consultants and developers, about the potentials of the mobile devices, it is often misinterpreted. Also, Nelson and Cooprider (1996) found that when there is a high level of shared knowledge and support in the organisation, it improves operational performance and shapes IT assimilation (Armstrong and Sambamurthy, 1991; Reich and Benbasat, 2000). Managers that understand the views of diverse entities within and outside the organisation are most likely to make the right choice for mobile marketing devices.

Extent of collaboration. Most organisations collaborate extensively because of the competitive advantages they enjoy. Collaboration in this context is defined as the engagement of various actors in a coordinated attempt to solve a problem, with shared commitment and goals. Collaborative works between various employees and sharing expertise information based on their areas of expertise. It also helps in achieving information flow during the adoption process. It was perceived that most small businesses do not collaborate even when collaboration help companies to understand their customers, employees, suppliers and perhaps partners. The problem with most small business managers is that they believe that if they collaborate, they might expose their ideas concerning the kind of mobile application they need. This may lead to competitive disadvantages because others may have access to information assumed to be essential to them. However, some managers have realised the benefits of collaboration as highlighted by some manager:

I am considering the best practice. You see, many SMEs do not like collaborating with others. [-] collaboration regarding what mobile application to adopt especially within the same line of business is very good even with competition (A12).

Yes, each staff in the organisation played a team role by working together to ensure that we get an application that will help meet our customers need (A15).

Participants A15, A22 and A23 also supported the above assertion made on collaboration. The finding implies that mobile marketing devices facilitate information exchange and enables relationships to be established among workgroups, customers, and other actors. 
Diversity in knowledge. The constant need for IT applications has made most organisations' knowledge intensive. Businesses no longer rely only on their knowledge, rather they have practically embraced knowledge from both internal and external context which allows the creation of new understanding about what mobile marketing applications to be adopted. Tenkasi and Boland (1998), note that one of the critical features of knowledge is the mutual learning of diverse experts to ensure that the complex activities associated with any new technological innovation are understood. This was echoed across cases:

[-] Most times we are the innovators driving the mobile app by communicating with the IT people or developers on a daily basis to ensure that the application is in line with our need. They cannot do it alone (A9).

We have to bring our knowledge, and constantly reviewing what the outcome is. That is when external advice comes to play (A12).

Although the finding was further supported by participants A6, A13 and A15, it was perceived that for any mobile marketing device to be successfully implemented requires the interaction of various internal and external actors by the manager in other to understand their views and plan for the best alternative in solving the intended problem. The finding implies that mobile marking technology adoption success will depend on how active SME managers can develop their unique capabilities, synergistically evaluate, integrate, utilise and exchange their unique knowledge with other employees and the external context.

\section{Environment}

Training period. Mobile marketing applications evolve so much that most times they become obsolete so quickly. Observation revealed that most SMEs go for training to equip themselves concerning the new application. It was revealed that most times the purpose of the training is for managers and employees to learn the most effective way the mobile application can add value to the business. However, evidence suggests that if the training is going to be time-consuming, it is highly unlikely that such an application will be considered. This was echoed across cases:

We may need to train if we finally go for it but this will depend on the time. We will try the mobile app if the time to train our staff is minimal (A11).

How much time do we require to master the application? If we are going to spend much time, we may adopt it (A2).

If you develop a product, it is always very difficult for you to use it at first [-]. It required learning (A9).

The finding demonstrates that most times SME managers are not patient enough to go through the hurdles of learning for a new application. Therefore, the majority consider the training period as a determinant of mobile marketing adoption. This finding is consistent with Rantapuska and Ihanainen (2008) found that managers see themselves as too busy and these most times hinder them from acquiring valuable information and training for IT decision-making instead they end up automating the existing ones.

Service delivery. Service delivery is defined as the capacity of mobile marketing devices to deliver efficiently and improve service delivery, the company's processes and profit. Managers interviewed noted that mobile marketing applications offered by vendors or suppliers would be considered if it disseminates reliable information, offers extended 
service, and permit urgent enquiry which is appropriate to clients. This was noted across cases:

[-] is the application going to be fast? [-] for us, speed is a determinant factor (A15).

The main reason why we would try a new mobile application is if it improves our process and delivery (A12).

The main aim we use this mobile app id to improve our process and delivery (A12).

Service delivery is an essential component of any firms' success (Song, 2003; Xu et al., 2011). Observation revealed such success ranges from enhancing client's responses to enquiries and problems, reducing labour cost; improve efficiency and productivity regarding speed which allows managers to gain some competitive advantages. According to Eze et al. (2018), the quality of services any new technology offers triggers the user from being poor prospects to adopters. This finding implies that if the mobile marketing devices are capable of improving the exchange of services, create new or improve customers' benefits, facilitate efficient service delivery and have the rewarding benefits for both the organisation and its customers, SMEs are willing to adopt it.

Customer satisfaction. Customer satisfaction is defined as the capacity of mobile marketing devices to provide services that are capable satisfy both the potential and real customers of the business. Mobile marketing technologies play essential roles in the buying process. Clients often rely on mobile marketing devices for relevant information about the products, make purchase, payment and provide follow up services (Moon, 2003). The finding suggests that customers were not only involved in mobile marketing technology adoption decision but most importantly, determine whether the businesses flourish or not. Considering the nature of small service businesses, it was highly perceived that managers were more concerned about their clients' satisfaction and retention which according to them determine the decisions to take. As pointed out by some participants, and supported by A14:

We see our customers like kings, is the mobile application capable of satisfying our customers' needs? This is very important (A11).

Mobile app is a means to an end we consider it as one of the capabilities to be able to relate with our customers and meet their needs[-] (A12).

It was further revealed that when these technology applications play pivotal roles in the buying process, their perceived performance remains critical to the business. This is consistent with the work of Moon (2003). This implies that small business managers would be eager to adopt mobile applications if it would help organisations to retain previous customers and acquire new ones.

\section{Competition}

Competition is defined as forces that constrain the continuity of a business. Most participants pointed out that competition shape mobile marketing technology adoption success:

Because they want to compete they just have to keep doing it (A5).

I was just worried that we might be left behind (A1).

As long as we want to be competitive, we just have to keep adopting new application (A9). 
In a similar vein, Khoumbati et al. (2006) note that competition has been recognized as an essential determinant of IT adoption in SMEs. Mobile marketing adoption was not only considered by SME managers as an option that increases market share but a way to promote their business and remain competitive. The finding suggests that the value small business managers attach to mobile marketing devices may be linked to its capacity to fight competition. This finding was consistent with Salmela and Turunen's (2003)study.

\section{Value anticipation}

Cost. Cost is not only defined regarding how second the mobile marketing application is, but how effective it is for communication purpose without having to spend so much, and provides the services other costly applications offer. Small businesses are known to be underprivileged because of limited resources. As such, one of their main objectives is to minimise cost and improve profit margin constantly. Therefore, the value most SME anticipates from mobile marketing devices is the capability to reduce cost. This factor was echoed by participants A2, A4, A6, A10, A11 and A23 and further supported:

You know we are small. If is reasonably cheap we will try it (A1).

Cost is one of the important factors we consider [-]. Would it help us to communicate effectively and reduce the total human resources? (A15).

We do not consider the need only but the cost (A20).

Will the app help us to keep the cost down? Will it save us money or make us appear more professional to our client? (A5).

The finding suggests that cost substantially influences the value SMEs to attach to mobile marketing devices. Similarly, Pirich et al.(2001) found that the choice of a small business owner to adopt any IT application depends on the cost-benefit analysis to help determine the long-term benefit. The finding implies that if the cost associated with the mobile marketing technology is perceived to be high, it is highly unlikely that such application will be adopted. This is consistent with previous studies (Lacovou et al., 1995; Ramayah et al., 2016; Madukua et al., 2016; Khoumbati et al., 2006).

\section{Business growth}

IT application improves productivity and assist SMEs in carrying out their businesses activities outside the firm and create new industries. Locke (2004; Eze et al., 2014) notes that improved business performance is likely to be experienced by those SMEs that have specific growth objectives Business growth is linked to staff strength, market share and return on investment tied to the IT application. Observation revealed that SMEs might take some time before engaging in mobile marketing. However, such devices should guarantee high value for the business. Participants note that this can only be achieved through growth:

One thing that motivates the search for the new application is growth. Would the application help us to increase our customer base? (A14)

Can the application help us acquire 30 clients or more in a few months we will try the new app (A5).

Is good for the company's growth? We just go ahead with that (A9). 
The analysis also revealed that environmental factors play a part in the business growth, which in turns shapes mobile marketing adoption:

If we know what is happening in that space, politically, social, technologically especially for us, those are the things that will make us decide what will be the growth area (A5).

Business growth was considered by managers regarding the value the mobile marketing devices add to the business. This ranges from market share; turn over, sales volume, some employees and customers acquired. In summary, the finding demonstrations that there is a relationship between mobile marketing technology implementation and business growth although, this may depend on how businesses measure their growth and the mobile devices used.

Differentiation. Technology differentiation is defined in this context as the capacity of the mobile marketing devices to help create unique services, or a niche in the market that rivals may find difficult to copy, and boost their chances of winning new customers. Advances in technology and globalisation have not only forced the world to be knowledgeable but continually created swift competition among businesses in a similar industry. Observation shows that small business managers may adopt mobile marketing devices because they might be afraid of been left behind. As such, technology differentiation was perceived to as a key influential factor. This was noted across cases:

Our need for a new mobile app largely depends on how it can help us reduce cost, [-], and create a niche in a market (A5).

Can the mobile app differentiate us from our competition? [-] If yes, it is highly likely that we would try the app (A13).

What we look at is the unique attributes of the app and the services it renders. Can it provide services that are unique to what we do? (A16).

This finding implies that the value anticipates of mobile marketing is associated with the capacity of the devices to differentiate an SME manager from those of competitors.

\section{Return on investment}

Return on investment in this context is associated with the profit the mobile marketing devices are capable of generating. It extends to the market values, residual income and future abnormal returns witnessed by a firm (Henderson et al., 2010; Eze et al., 2012). Evidence from the analysis suggests that most privately owned companies are profitoriented, and it is highly unlikely that business that does not generate a return on investments and increases market shares will be in business for a long time. This was echoed across cases:

Anything called technology that cannot help us maximise our profit, would not be considered (A20).

If we invest \#10,000, as long as it yields a return of \#15,000 we will adopt it (A23).

Business is all making profit. If you are not making profit, short the company down and go and sleep (A9).

Similar comments were made by participants A2, A5, A12, A13 and A14, and others. In support of this assertion, studies (Lim et al., 2011; Cavusoglu et al., 2004) have examined the 
financial return on IT and found that return on investment triggers investment in technology. Profit is linked directly to customer satisfaction, and businesses tend to be profitable where the mobile marketing applications adopted provides services aimed at meeting their needs and those of their customers. The value small business managers attach to mobile marketing devices is directly linked to how much profit these devices generate.

\section{Conclusions and implications}

\section{Conclusion}

The study revealed 16 factors influencing the adoption of mobile marketing technology adoption based on the extended TOE framework developed in this study. Factors related to the technology context include operational effectiveness, adaptive capability, simplicity, safety issues and expandability, while organisation context-related factors include shared understanding, the extent of business collaboration and diversity in knowledge. Also, training period, service delivery, customer satisfaction and competition are factors associated with the environmental context, and value anticipation related factors include cost business growth, differentiation and return on investment. However, while these factors influence mobile marketing technology adoption, the extent to which these factors shape mobile marketing adoption varies from technology, organisation environment and value anticipation contexts. For example, technology context-related factors accounted for 73 per cent of the total supporting cases; organisation context-related factors accounted for 61 per cent of the total supporting cases, while environment and value anticipated factors represent 80 and 58 per cent of the total supporting cases, respectively.

\section{Implications}

The extended TOE framework developed in this study which was to understand the factors shaping the adoption of mobile marketing technology in SMEs have some implications. The framework provides a frame of references (Agarwel, 2000; Macredie and Mijinyawa, 2011) to understand factors shaping mobile marketing technology adoption. The operational definitions of the codes and the factors depicted in the framework may serve as an analytical tool for scholars to understand and explain factors influencing mobile marketing technology adoption. The study has been able to identify additional codes and the associated factors which fall outside the three elements of TOE frameworks. The code and the associated factors aided the extension of the TOE framework thereby adding and enriching the existing variables associated with TOE. According to Macredie and Mijinyawa (2011), the inability of researchers to effectively defined factors and theoretical concepts has been an issue in the analysis and validation of the factors. Therefore, the theoretical and empirical constructs and the associated factors can be used to develop a hypothesis to validate the relationships between the constructs and the factors. It is possible for researchers to carry out a cross-sectional or comparative study to validate and better understand factors influencing the adoption of mobile marketing devices.

From the practical point of view, Dedrick and West (2003) argued that models and frameworks are relevant and useful for practitioners and decision-makers seeking to develop models for IT application. Therefore, the framework could also serve as a frame of reference to SMEs seeking to have a deep insight and a common understanding of the factors influencing the adoption of mobile marketing devices. Also, the framework could be used by managers for a strong justification for the courses of action (Banbaset and Moore, 1992; Macredie and Mijinyawa, 2011) in the adoption of mobile marketing technology. SME managers and other decision-makers could use the argument in the study and the practical insight in this study to create awareness among staff on the benefits and challenges 
associated with the use of mobile marketing technologies. Finally, because the TOE framework has a strong exploratory and explanatory capabilities, the framework provides room for the development of a diverse range of insights into the factors shaping the adoption of mobile marketing technology adoption. SMEs and other decision makers can apply the framework and further identify various concepts associated with the technological, organisational and environmental and value anticipation related factors of mobile marketing technology adoption.

\section{Research limitations}

The limitation of this study emerged because of the use of qualitative methodologies about the research design, rigour in the collection and management of the large volume of the raw data, the data analysis and the credibility of the findings. This may lead to unforeseen respondent and research bias in the data analysis which may lead to a limited understanding of alternatives and insights into the factors influencing the adoption of mobile marketing (Macredie and Mijinyawa, 2011). Hence, other measures and approaches such as case study and mix-method could be deployed to validate the findings further.

Regardless of the confidence of the researchers in the use of thematic data analysis approach and the findings presented in this study, the framework has its limitation. From the data analysis, evidence suggests that factors presented in this paper are limited. There are other factors which were identified during the analysis but were not included because of their limited supporting cases and evidence. Therefore, more studies are required in this area in other to identify other factors prevalent within the service sectors and other industries or organisations in Nigeria using a different methodological approach.

Although, it can be argued that the framework has analytical generalizability because of the theory building approach deployed in identifying the factors. However, one of the limitations of qualitative study has been the issue of theoretical generalizability of the framework. Hence, the generalizability of the formwork needs to be established across a broader range of the population. Future studies may apply confirmatory statistical techniques to test and ascertain the validity and reliability of the framework across a broader population of mobile marketing technology adopters in Nigeria. Such studies may be used as a benchmark for the theoretical constructs and the factors that may lead to the success or failure of mobile marketing technology adoption.

\section{References}

Aboelmaged, M.G. (2010), "Predicting e-procurement adoption in a developing country", Industrial Management and Data Systems, Vol. 110 No. 3, pp. 341-392.

Adams, D.A., Nelson, R.R. and Todd, P.A. (1992), "Perceived usefulness, ease of use, and usage of information technology: a replication”, MIS Quarterly, Vol. 16 No. 2, pp. 227-247.

Ajzen, I. and Fishbein, M. (Eds) (1980), Understanding Attitudes and Predicting Social Behaviour, Prentice-Hall, Upper Saddle River, NJ.

Alshamaila, Y., Papagiannidis, S. and Li, F. (2013), "Cloud computing adoption by SMEs in the North East of England: a multi-perspective framework", Journal of Enterprise Information Management, Vol. 26 No. 3, pp. 250-275.

Amirkhanpour, M., Vrontis, D. and Thrassou, A. (2014), "Mobile marketing: a contemporary strategic perspective", International Journal of Technology Marketing, Vol. 9 No. 3, pp. 252-269.

Armstrong, C. and Sambamurthy, V. (1991), "Technology assimilation in firms: the influence of senior leadership and IT infrastructures", Information Systems Research, Vol. 17 No. 1, pp. 99-120. 
Andries, P. and Debackere, K. (2006), "Adaptation in new technology-based ventures: insights at the company level", International Journal of Management Reviews, Vol. 8 No. 2, pp. 91-112.

Agarwel, R. (2000), "Individual acceptance of information technologies", in Zmud, R. (Ed.), Framing the Domais of Let Management: Projecting the Future through the Past, Pinnacle Education Resources, Cincinnati, OH, pp. 85-104.

Awa, H.O., Eze, S.C., Maclayton, D.W. and Okoye, J.C. (2012), "User voice and democracy in value creation: integrating competencies with innovation development", International Journal of Management, Vol. 29 No. 1.

Balasubramanian, S., Peterson, R.A. and Jarvenpaa, S.L. (2002), "Exploring the implications of mcommerce for markets and marketing", Journal of Academy of Marketing Science, Vol. 30 No. 4, pp. 348-361.

Baker, J. (2012), “The technology- organisation-environment framework”, Information Systems Theory, Springer.

Banbaset, I. and Moore, G.C. (1992), "Development of measures for studying emerging technologies", Proceeding of the 25 HI International Conference on Systems Science, Vol 4, Information Systems, IEEE Computer Society, Washington, DC, pp. 315-324.

Boyatzis, R. (1998), Transforming Qualitative Information: Thematic Analysis and Code Development, Sage Publication, London.

Brown, D.H. and Lockett, N. (2004), "Potential of critical e-applications for engaging SMEs in ebusiness: a provider perspective", European Journal of Information Systems, Vol. 13 No. 1, pp. 21-34.

Castro, M.L., Montoro-Sanchez, A. and De-Urbina-Criado, M.O. (2010), "Innovation in service industries: current and future trend", The Service Industries Journal, Vol. 31 No. 1, pp. 7-30.

Cavusoglu, H., Mishra, B. and Raghunathan, S. (2004), “A model for evaluating IT security investment”, Communications of the Acm, Vol. 47 No. 7, pp. 87-92.

Charoensukmongkol, P. and Sasatanun, P. (2017), "Social media use for CRM and business performance satisfaction: the moderating roles of social skills and social media sales intensity", Asia Pacific Management Review, Vol. 22 No. 1, pp. 25-34.

Chau, P.Y.K. and Tam, K.Y. (1997), "Factors affecting the adoption of open systems: an exploratory study", MIS Quarterly, Vol. 21 No. 1, pp. 1-24.

Davis, F.D. (1989), "Perceived usefulness, perceived ease of use and acceptance of information technology", MIS Quarterly, Vol. 3 No. 3, pp. 319-340.

Dedrick, J. and West, J. (2003), "Perceived usefulness, perceived ease of use, and user acceptance of information technology”, MIS Quarterly, Vol. 13 No. 3, pp. 319-339.

Dwivedi, Y.K., Papazafeiropoulo, A., Chuang, T.T., Nakatani, K. and Zhou, D. (2009a), "An exploratory study of the extent of information technology adoption in SMEs: an application of upper echelon theory", Journal of Enterprise Information Management, Vol. 22 Nos 1/2, pp. 183-196.

Earl, M. and Feeny, D. (2012), "How to be a CEO for the information age", Sloan Management Review, Vol. 14 No. 2, pp. 11-23.

Eze, S.C. and Chinedu-Eze, C.V. (2018), "Examining information and communication technology (ICT) adoption in SMEs: a dynamic capabilities approach", Journal of Enterprise Information Management, Vol. 31 No. 2, pp. 338-356.

Eze, S.C., Duan, Y. and Chen, H. (2012), "Factors affecting emerging ICT adoption in SMEs: an actornetwork theory analysis", International Conference on E-business Technology and Strategy (ICETS), Tanjin.

Eze, S.C., Duan, Y. and Chin, H. (2014), "Examining emerging ICT's adoption in SMEs from a dynamic process approach", Information Technology and People, Vol. 27 No. 1, pp. 63-82. 
Eze, S.C., Olatunji, S., Chinedu-Eze, V.C. and Bello, A.O. (2018), "Key success factors influencing SME managers' information behaviour on emerging ICT (EICT) adoption decision-making in UK SMEs", The Bottom Line, Vol. 31 Nos 3/4, pp. 250-275.

Eze, S.C., Awa, H., Okoye, J., Emecheta, B. and Anazodo, R. (2013), "Determinant factors of information communication technology (ICT) adoption by government-owned universities in Nigeria", Journal of Enterprise Information Management, Vol. 26 No. 4, pp. 427-443.

Fitzgerald, B. and Kenny, T. (2003), "Open source software in the trenches: lessons from large-scale implementation", Proceeding of the 24th International Conference on Information Systems, December 2003, The Association for Information Systems, pp. 316-326.

Gilmore, A. and Carson, D. (2007), "Teaching and research in small business enterprise marketing: a critique and some alternatives", in Hine, D. and Carson, D. (Eds), Innovative Methodologies in Enterprise Research, Edward Elger, Cheltenham.

Gholami, B., Kaviani, F. and Zabihi, E. (2009), "Web 2.0, a boost in IT infrastructure flexibility and team collaboration", Second International Conference on Computer and Electrical Engineering, IEEE Computer Society.

Grandon, E.E. and Pearson, J.M. (2004), "Electronic commerce adoption: an empirical study of small and medium US businesses", Information and Management, Vol. 42 No. 1, pp. 197-216.

Gupta, P., Seetharaman, A. and Raj, J.R. (2013), "The usage and adoption of cloud computing by small and medium businesses", International Journal of Information Management, Vol. 33 No. 5, pp. 861-874.

Gutierrez, A., Boukrami, E. and Lumsden, R. (2015), “Technological, organisational and environmental factors are influencing managers' decision to adopt cloud computing in the UK", Journal of Enterprise Information Management, Vol. 28 No. 6, pp. 788-807.

Harvie, H. (2010), "East Asian production networks: the role and contribution of SMEs", International Journal of Business and Development Studies, Vol. 2 No. 1, pp. 27-62.

Henderson, B.C., Kobelsky, K., Richardson, V. and Smith, R.E. (2010), "The relevance of information technology expenditure", Journal of Information Systems, Vol. 24 No. 2, pp. 39-77.

Hong, W., Thong, J.L., Chasalow, L.C. and Dhillon, G. (2011), "User acceptance of agile information systems: a model and empirical test", Journal of Management Information Systems, Vol. 28 No. 1, pp. 235-275.

Inegbedion, H.E. (2018), "Factors that influence customers' attitude towards electronic banking in Nigeria", Journal of Internet Commerce, doi: 10.1080/15332861.2018.1463482.

Inegbedion, H.E., Obadiaru, D.E. and Bello, D.V. (2016), "Factors that influence consumers' attitude towards internet buying in Nigeria", Journal of Internet Commerce, Vol. 15 No. 4, pp. 353-375.

Johnston, E. Begg, S. and Tanner, M. (2013), "Exploring the factors influencing the adoption of open", available at: $\mathrm{https://files.eric.ed.gov/fulltext/EJ1071356.pdf}$

Khoumbati, K., Themistocleous, M. and Irani, Z. (2006), "Evaluating the adoption of enterprise application integration in health- care organisation", Journal of Management Information Systems, Vol. 22 No. 4, pp. 69-108.

Kim, G.S., Park, S.B. and Oh, J. (2008), “An examination of factors influencing consumer adoption of short message service (SMS)”, Psychology and Marketing, Vol. 25, pp. 769-786.

Kuan, K.K. and Chau, P.Y. (2001), "A perception-based model for EDI adoption in small businesses using a technology- organisation-environment framework", Information and Management, Vol. 38 No. 8, pp. 507-521.

Lacovou, A.L., Benbasat, I. and Dexter, A. (1995), "Electronic data interchange and small organisations: Adoption and impact of technology", MIS Quarterly, Vol. 19 No. 4, pp. 465-485.

Lamarre, A., Galarneau, S. and Harold-Boeck, H. (2012), "Mobile marketing and consumer behaviour: current research trend", International Journal of Latest Trends in Computing, Vol. 3 No. 1, pp. 1-9. 
Lee, J. (2004), "Discriminant analysis of technology adoption behaviour: a case of internet technologies in small business", Journal for Computer Information Systems, Vol. 44 No. 4, pp. 57-66.

Leppäniemi, M. and Karjaluoto, H. (2008), "Mobile marketing: from marketing strategy to mobile marketing campaign implementation”, International Journal of Mobile Marketing, Vol. 3 No. 1, pp. 50-61.

Leppäniemi, M., Sinisalo, J. and Karjaluoto, H. (2006), "A review of mobile marketing research", International Journal of Mobile Marketing, Vol. 1 No. 1, pp. 30-40.

Levy, M. and Powell, P. (2003), "Exploring SME internet adoption: towards a contingent model", Electronic Markets, Vol. 10 No. 3, pp. 265-276.

Li, X., Troutt, M.D., Brandyberry, A. and Wang, T. (2011), "Decision factors for the adoption and continued use of online direct sales channels among SMEs", Journal of the Association for Information Systems, Vol. 12 No. 1, pp. 1-31.

Lian, J.W., Yen, D.C. and Wang, Y.T. (2014), "An exploratory study to understand theoretical factors affecting the decision to adopt cloud computing in Taiwan hospital", International Journal of Information Management, Vol. 34 No. 1, pp. 28-36.

Liao, J., Welsch, H. and Stoica, M. (2003), "Organisational absorptive capacity and responsiveness: an empirical investigation of growth-oriented SMEs", Entrepreneurship Theory and Practice, Vol. 28 No. 1, pp. $63-85$.

Lim, J.-E., Dehning, B., Richardson, V.J. and Smith, R.E. (2011), “A meta-analysis of the effects of IT investment on firm financial performance", Journal of Information Systems, Vol. 25 No. 2, pp. 145-169.

Lindermann, N., Valcarcel, S., Schaarschmidt, M. and Kortzfleisch, H.V. (Eds) (2009), SME 2.0: Roadmap toward Web 2.0 Open Innovation in SME-networks - A Case Study Based Research Framework, Springer Publishers, Boston, MA.

Lip-Sam, T. and Hock-Eam, L. (2011), "Estimating the determinants of B2Be-commerce adoption among small and medium enterprises", International Journal of Business and Society, Vol. 12 No. 1, pp. 15-30.

Locke, S. (2004), "ICT adoption and SME growth in New Zealand", The Journal of American Academy of Business, Vol. 3 No. 13, pp. 93-102.

MacLennan, L. and Van Belle, P. (2014), "Factors affecting organisational adoption of service-oriented architecture (SOA)", Information Systems and e-Business Management, Vol. 12 No. 1, pp. 71-100.

Ma, J., Suntornpithug, N. and Karaatli, G. (2009), "Mobile advertising?", Does It Work for Everyone? International Journal of Mobile Marketing, Vol. 4 No. 2, pp. 28-35.

Macredie, R.D. and Mijinyawa, K. (2011), "A theory -grounded framework of open source software adoption in SMEs", European Journal of Information Systems, Vol. 20, pp. 237-250.

Madukua, D.K., Mpinganjirab, M. and Duhca, H. (2016), "Understanding mobile marketing adoption intention by South African SMEs: a multi-perspective framework", International Journal of Information Management, Vol. 36 No. 5, pp. 711-723.

Markus, M.L. and Tanis, C. (2000), "The enterprise systems experience-from adoption to success. Framing the domains of IT research: glimpsing the future through the past", Pinnaflex Educational Resources, Vol. 173, p. 207.

Martin, L. and Matlay, H. (2001), "Blanket approaches to promoting ICT in small firms: some lessons from the IDT ladder adoption model in the UK", Internet Research, Electronic Networking Applications and Policy, Vol. 11 No. 5, pp. 399-410.

Martin, L.M. and Halstead, A. (2004), “Attracting micro enterprises to learning”, Community Initiatives or Growth Community, Work and Family, Vol. 7 No. 1, pp. 29-42.

Mehrtens, J., Cragg, P.B. and Mills, A.M. (2001), "A model of internet adoption by SMEs”, Information and Management, Vol. 39 No. 3, pp. 165-176. 
Miles, M.B. and Huberman, A.M. (1994), Qualitative Data Analysis: An Expanded Sourcebook, Sage Publication, Thousand Oaks, CA.

Milla, C.J.M. and Choi, C.J. (2011), "The innovative feature of service industries: (anti-) globalisation and commensuration", The Service Industries Journal, Vol. 31 No. 1, pp. 21-38.

Mobile Marketing Association (2015), "MMA updates the definition of mobile marketing", available at:

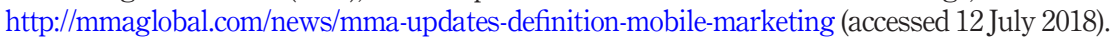

Moon, Y. (2003), "Don't blame the computer when self -disclosure moderates the self-serving bias", Journal of Consumer Psychology, Vol. 13 Nos 1/2, pp. 125-137.

Moore, G. and Benbasat, I. (1991), "Development of an instrument to measure the perceptions of adoption in information technology innovation", Information Systems Research, Vol. 2 No. 3, pp. 192-222.

Mutula, S.M. and Brakel, P.V. (2006), "E-readiness of SMEs in the ICT sector in Botswana concerning information access", The Electronic Library, Vol. 24 No. 3, pp. 402-417.

Nasco, S. and Bruner, G.C. II. (2008), "Comparing consumer responses to advertising and nonadvertising mobile communications", Psychology and Marketing, pp. 822-838.

Nelson, K.M. and Cooprider, J.G. (1996), "The contribution of shared knowledge to IS group performance", MIS Quarterly, Vol. 20 No. 4, pp. 409-429.

Nguyen, T.H., Newby, M. and Macaulay, M.J. (2015), "Information technology adoption in small business: confirmation of a proposed framework", Journal of Small Business Management, Vol. 53 No. 1, pp. 207-227.

Oliveira, T. and Martins, M.F. (2011), “A literature review of information technology adoption models at firm level”, The Electronic Journal Information Systems Evaluation, Vol. 14, pp. 110-121.

Ojeme, S. and and Onuba, I. (2010), “CBN set up 200bn SME credit guarantee scheme”, The Punch, 19 April, p. 17.

Ongori, H. and Migiro, S.O. (2010), "Information and communication technology adoption: literature review", Journal of Chinese Entrepreneurship, Vol. 2 No. 1, pp. 93-100.

Osagie, C. (2010), "Embrace entrepreneurship, SMEDAN urges youths this day”, Vol. 15 No. 5483, p. 36.

Parellada, F.S., Soriano, D.S. and Lhuarng, K.-. (2011), "An overview of the service industries future priorities: linking past and future”, The Service Industrial Journal, Vol. 31 No. 1, pp. 1-6.

Park, J. and Yang, S. (2006), "The moderating role of consumer trust and experiences: value driven usage of mobile technology”, International Journal of.Mobile Marketing, Vol. 1 No. 2, pp. 24-32.

Parker, C.M. and Castleman, T. (2009), "Small firm e-business adoption: a critical analysis of theory", Journal of Enterprise Information Management, Vol. 22 Nos 1/2, pp. 167-182.

Pavlou, P.A. and Fygenson, M. (2006), "Understanding and predicting electronic commerce adoption: an extension of the theory of planned behaviour", MIS Quarterly, Vol. 30 No. 1, pp. 115-143.

Premkumar, G. (2003), "A meta-analysis of research on information technology implementation in small business", Journal of Organizational Computing, Vol. 13 No. 2, pp. 91-121.

Pirich, A., Knuckey, S. and Campbell, J. (2001), “An interface between entrepreneurship and innovation: New Zealand SMEs perspective”, DRUID Nelson and Winter Conference, Aalborg University, Denmark.

Polites, G.L. and Karahanna, E. (2012), "Shackled to the status quo: the inhibiting effects of incumbent system habit, switching cost, and inertia on new system acceptance”, MIS Quarterly, Vol. 36 No. 1, pp. 21-42.

Porter, M. and Millar, V. (1985), "How information gives you a competitive advantage", Harvard Business Review, Vol. 63 No. 4, pp. 149-160.

Ramayah, T., Ling, N.S., Taghizadeh, S.K. and Rahman, S.A. (2016), "Factors influencing SMEs website continuance intention in Malaysia”, Telematics and Informatics, Vol. 33 No. 1, pp. 150-164. 
Ramdani, B. and Kawalek, P. (2008), "Exploring SMEs' adoption of broadband in the Northwest of England”, in Ramirez-Correa, P.E., Rondan-Catalũna, F.J. and Arenas-Gaitán, J. (Eds), Handbook of Research on Global Diffusion of Broadband Data Transmission, IGI Global, Hershey, PA, pp. 504-523.

Rantapuska, T. and Ihanainen, O. (2008), "Knowledge use in ICT investment decision making of SMEs", Journal of Enterprise Information Management, Vol. 21 No. 6, pp. 585-596.

Rogers, E.M. (1995), Diffusion of Innovations, 4th ed., The Free Press, New York, NY.

Ritchies, B. and Brindley, C. (2005), "ICT adoption by SMEs: implication for relationships and management", New Technology, Work and Employment, Vol. 20 No. 3, pp. 205-217.

Reich, B.H. and Benbasat, I. (2000), "Factors that influence the social dimension of alignment between business and information technology objectives", MIS Quarterly, Vol. 24 No. 1, pp. 81-111.

Rui, G. (2007), "Information systems innovation adoption among organisations: a match-based framework and empirical studies", doctoral thesis, University of Singapore, Singapore.

Ruivo, P., Oliveira, T. and Neto, M. (2014), "Examine ERP post-implementation stages of use and value: empirical evidence from Portuguese SMEs", International Journal of Accounting Information Systems, Vol. 15 No. 2, pp. 166-184.

Schultze, U. and Avital, M. (2011), "Designing interviews to generate rich data for information systems research", Information and Organization, Vol. 21 No. 1, pp. 1-16.

Shankar, V. and Balasubramanian, S. (2009), "Mobile marketing: a synthesis and prognosis", Journal of Interactive Marketing, Vol. 23 No. 2, pp. 118-129.

Shankar, V., Venkatesh, A., Hofacker, C. and Naik, P. (2010), "Mobile marketing in the retailing environment: current insight and future research avenue", Journal of Interactive Marketing, Vol. 24 No. 2, pp. 111-120.

Shareef, M.A., Dwivedi, Y.K., Kumer, V.V. and Kumar, U. (2017), "Content design of advertising for consumer exposure: mobile marketing through short messaging services", International Journal of Information Management, Vol. 37 No. 4, pp. 257-268.

Song, H. (2003), "E-service at FedEx", Communications of the ACM, Vol. 46 No. 6, pp. 45-46.

Strom, R., Vendel, M. and Bredican, J. (2014), "Mobile marketing: a literature review on its value for consumers and retailers", Journal of Retailing and Consumer Services, Vol. 21, pp. 1001-1012.

Sultan, F., Rohm, A.J. and Gao, T. (2009), "Factors influencing consumers' acceptance of mobile marketing: a two -country study of youth markets", Journal of Interactive Marketing, Vol. 23 No. 4, pp. 308-320.

Stump, R.L., Gong, W. and Li, Z. (2008), "Exploring the digital divide in mobile-phone adoption levels across countries: do population socioeconomic traits operate in the same manner as their individual -level demographic counterparts?", Journal of Micromarketing, Vol. 28 No. 4, pp. 397-412.

To, M.L. and Ngai, E.W. (2006), "Predicting the organizational adoption of B2C e-commerce: an empirical study”, Industrial Management and Data Systems, Vol. 106 No. 8, pp. 1133-1147.

Teo, S.Y. and Pan, S.L. (2008), "Understanding the influence of social integration in enterprise systems use", Journal of Enterprise Information Management, Vol. 21 No. 5, pp. 493-511.

Teo, T.H.S., Srivastava, S.C., Ranganathan, C. and Loo, J.W.K. (2011), "A framework for stakeholder oriented mindfulness: Case of RFID implementation at YCH group, Singapore", European Journal of Information Systems, Vol. 20 No. 2, pp. 201-220.

Thong, J.Y. (1999), “An integrated model of information systems adoption in small businesses”, Journal of Management Information Systems, Vol. 15 No. 4, pp. 187-214.

Thong, J.Y., Yap, C.S. and Raman, K. (1996), "Top management support, external expertise and information systems implementation in small businesses", Information Systems Research, Vol. 7 No. 2, pp. 248-267. 
Thurasamy, R., Mohamad, O., Omar, A. and Marimuthu, M. (2009), “Technology adoption among small and medium enterprises (SMEs): a research agenda", Proceedings of World Academy of Science, Engineering and Technology, Vol. 41, pp. 2070-3740.

Weng, M. and Lin, C. (2011), "Determinants of green innovation adoption for small and medium-size enterprises (SMES”, ). African Journal of Business Management, Vol. 5 No. 22, pp. 9154-9163.

Williams, M., Dwivedi, Y.K., Lal, B. and Schwarz, A. (2009), "Contemporary trends and issues in IT adoption and diffusion research", Journal of Information Technology, pp. 210-241.

$\mathrm{Xu}$, J., Benbasat, I. and Cenfetelli, R. (2011), "The effects of service and consumer product knowledge on online customer loyalty", Journal of the Association for Information Systems, Vol. 12 No. 11, pp. 741-766.

Xu, M., Rohatgi, R. and Duan, Y. (2007), "E-business adoption in SMEs: some preliminary findings from electronic component industry", International Journal of E-Business Research, Vol. 3 No. 1, pp. 74-90.

Venkatesh, V. and Davis, F. (1996), "A model of the antecedents of perceived ease of use: development and test”, Decision Science, Vol. 27 No. 3, pp. 451-481.

Venkatesh, V., Morris, M.G., Davis, G.B. and Davis, F.D. (2003), "User acceptance of information technology: toward a unified view", MIS Quarterly, Vol. 27 No. 3, pp. 425-478.

Yousafzai, S. and Yani-De-Soriano, M. (2012), "Understanding customer-specific factors are underpinning internet banking adoption”, International Journal of Bank Marketing, Vol. 30 No. 1, pp. 60-81.

Zhu, K., Kraemer, K. and Xu, S. (2003), "Electronic business adoption by Europe firms: a cross-country assessment of the facilitators and inhibitors", European Journal of Information Systems, Vol. 12 No. 4, pp. 251-256.

\section{Further reading}

Dwivedi, Y.K., Papazafeiropoulo, A., Supyuenyong, V., Islam, N. and Kulkarni, U. (2009b), "Influence of SME characteristics on knowledge management processes: the case study of enterprise resource planning service providers", Journal of Enterprise Information Management, Vol. 22 Nos 1/2, pp. 63-80.

Gable, G.C. (2018), "Integrating case study and survey research method: an example in information systems", European Journal of Information Systems, Vol. 3 No. 2, pp. 112-126.

E-marketer (2014), "Driven by Facebook and Google, mobile ad market soars 105 per cent in2013", available at: www.emarketer.com/Article/Driven-by-Facebook-Google-Mobile-Ad-Market-Soars10537-2013/1010690\#sthash.80tPysOG.dpuf (accessed 12 July 2018).

Silva, L. (2007), "Post-positivist review of technology acceptance model", Journal of the Association for Information Systems, Vol. 8 No. 4, pp. 255-266.

Corresponding author

Sunday C. Eze can be contacted at: eze.sunday2010@gmail.com

For instructions on how to order reprints of this article, please visit our website: www.emeraldgrouppublishing.com/licensing/reprints.htm Or contact us for further details: permissions@emeraldinsight.com 


\section{AUTHOR QUERIES}

\section{AUTHOR PLEASE ANSWER ALL QUERIES}

AQau - Please confirm the given-names and surnames are identified properly by the colours.

=Given-Name, $\mathbf{a}=$ Surname

The colours are for proofing purposes only. The colours will not appear online or in print.

AQ1-Please note that the following citations are not listed in the reference list. Please provide full details for these citations: Rogers, 1983; Ramdani et al., 2013; Tornatzky and Fleisher 1990; Nguyen, 2009; Premkumar and Roberts, 1999; Fereday and Muir-Cochrane, 2006; Miranda and Sauder, 2003; Tenkasi and Boland, 1998; Salmela and Turunen, 2003; Silver, 2007; Shane 2003.

AQ2- Please provide first column head for Tables IV-VII. 